See discussions, stats, and author profiles for this publication at: https://www.researchgate.net/publication/264673514

Identifying core habitat before it's too late: The case of Bombina variegata, an internationally endangered amphibian

Article in Biodiversity and Conservation · March 2014

DOI: 10.1007/s10531-014-0624-7

\section{CITATIONS}

18

6 authors, including:

Ben C Scheele

Australian National University

102 PUBLICATIONS 489 CITATIONS

SEE PROFILE

17. Jan Hanspach

Leuphana University Lüneburg

106 PUBLICATIONS 2,386 CITATIONS

SEE PROFILE
READS

264

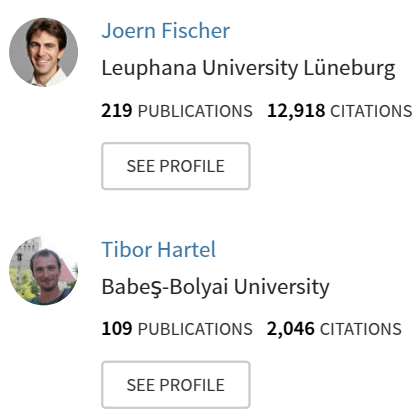

Some of the authors of this publication are also working on these related projects:

Project $\quad$ Programme on Ecosystem Change and Society (PECS) View project

Project A network model of institutional fit between actor networks and cross-sector governance issues View project 


\title{
Identifying core habitat before it's too late: the case of Bombina variegata, an internationally endangered amphibian
}

Biodiversity and Conservation 2014, 23, 3, 775-780

B. C. Scheele, C. E. Boyd, J. Fischer, A. W. Fletcher, J. Hanspach, T. Hartel

\begin{abstract}
Impending land-use change, including agricultural intensification, is increasingly threatening biodiversity in traditional rural landscapes. To ensure the persistence of species that are vulnerable to land-use change it is necessary to identify and protect high quality habitat before species start to decline. Given that many potentially vulnerable species are still widespread in traditional rural landscapes, it is difficult to identify particularly important locations for such species. Presenceabsence data on a given species may have limited application in such cases. As an alternative to presence-absence data, we investigated the influence of environmental variables on the physiological body condition of Bombina variegata (yellow-bellied toad) in a traditional rural landscape in Transylvania, Romania. The species is internationally endangered but remains common throughout our study area. Based on body condition measurements of 550 toads from 60 ponds, we found that toads in forest ponds had significantly better body condition than those in pasture ponds, indicating that forest landscapes provided particularly high quality habitat. We suggest that measures such as body condition — in addition to distribution data—could have considerable application in identifying high quality habitat for other species that are still widespread in traditional landscapes, but have declined in modernised, but otherwise similar landscapes.
\end{abstract}

Keywords: Amphibian decline, Body condition, Land-use change, Traditional agriculture, Yellowbellied toad 


\section{B. C. Scheele}

Fenner School of Environment and Society, Australian National University, Forestry Building [48], Canberra, ACT 0200, Australia, e-mail: ben.scheele@anu.edu.au

C. E. Boyd, J. Fischer, A. W. Fletcher, J. Hanspach, T. Hartel

Department of Ecology, Faculty of Sustainability, Leuphana University Luneburg, Scharnhorststraße 1, 21335 Lüneburg, Germany

\section{T. Hartel}

Environmental Science Department, Sapientia Hungarian University of Transylvania, Cluj-Napoca, Romania

\section{Introduction}

Traditional rural landscapes occur around the world and commonly support high biodiversity, including many rare and endangered species (Plieninger and Bieling 2012). Increasingly, growing food demands (Benton et al. 2011) and local development aspirations (Mikulcak et al. 2013) are driving land-use change and infrastructural development in many of these landscapes, representing a substantial threat to biodiversity (Fischer et al. 2012; Dullinger et al. 2013). Given the sensitivity of many farmland species to land-use change, a key challenge is to identify core habitat and develop conservation strategies before species start to decline. A common approach to identifying important landscape elements for vulnerable species is to use occupancy or abundance data. However, such approaches may be limited in landscapes where target species remain ubiquitous because identifying true absence sites at relevant spatial scales is difficult. Furthermore, discerning the relative quality of occupied patches using abundance data is difficult because accurate counts are challenging to obtain for many species.

In this note, we use an alternative method, namely the comparison of physiological body condition across environmental gradients, to investigate habitat quality. As a case study, we investigated a 
traditional rural landscape (Southern Transylvania, Romania), focusing on the yellow bellied toad,

Bombina variegata (Fig. 1). B. variegata is an interesting target species because it is: (i)

internationally endangered (European Union Habitats Directive Annex II and IV); (ii) largely

dependent on small, ephemeral water bodies that are susceptible to desiccation (Barandun and Reyer 1997); and (iii) vulnerable to land-use change including land abandonment and land-use intensification (Canessa et al. 2013). We define suitable habitat as areas with biotic and abiotic conditions favourable to the ongoing perpetuation of $B$. variegata populations. However, we hypothesize that biotic conditions and resource availability are not evenly distributed across the study region, and that therefore, better body condition will be indicative of particularly high quality habitat (cf. Pope and Matthews 2002; Hinam and Clair 2008; Janin et al. 2011).

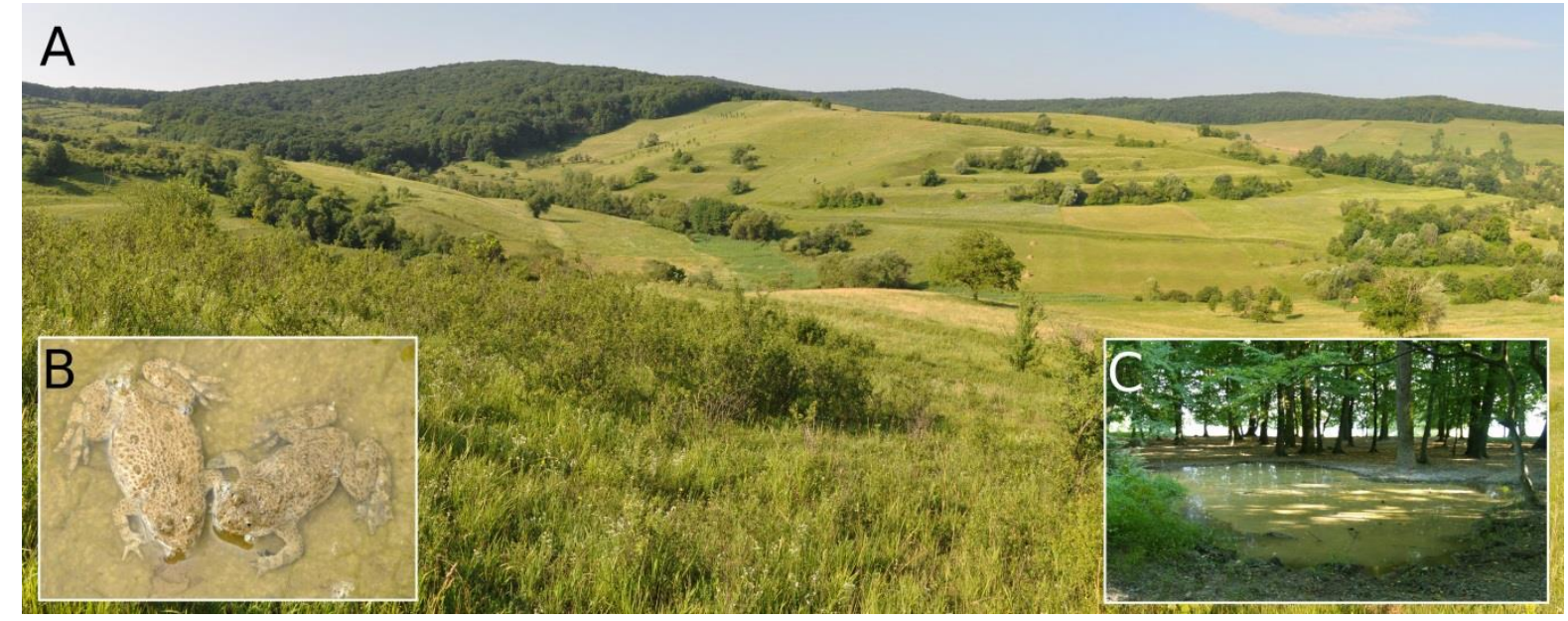

Fig. 1 (A) Bombina variegata occurs throughout the traditional rural landscapes of Southern

Transylvania, Romania. (B) B. variegata from a pasture pond. (C) A sampled forest pond

\section{Methods}

Our study area is hilly (altitude ca. $350-700 \mathrm{~m}$ ), covers approximately $3,000 \mathrm{~km}^{2}$, and is used primarily for traditional livestock grazing, agriculture, and forestry (see Fischer et al. 2012 for details). In contrast to Western Europe, where B. variegata has declined dramatically (Kuzmin et al. 2009), the species remains abundant and widespread throughout the region (Hartel and von Wehrden 2013). 
In May 2013, we resurveyed 168 ponds that were occupied by B. variegata in 2011-2012 (Hartel and von Wehrden 2013). The spring of 2013 was unusually dry, and only $21.5 \%$ of forest ponds and 5.5 $\%$ of pasture ponds that previously supported toads contained water. To increase sample size, we identified additional sites where the species was present, in both pastures and forests. In total, we sampled 60 ponds: 30 in open pastures and 30 in forests (ca. $50 \mathrm{~m}$ from the forest edge in three cases and at >100 $\mathrm{m}$ in all other cases). Hartel (2008) had shown that individual toad movements are common up to distances of $200 \mathrm{~m}$, but decrease sharply after $300 \mathrm{~m}$. Therefore we ensured that all surveyed ponds were separated by $>500 \mathrm{~m}$. We measured snout-urostyle length ((SUL) dial calliper, $0.1 \mathrm{~mm}$ precision) and body mass (electronic balance, $0.1 \mathrm{mg}$ ) for $7-10$ individuals at each pond. In total, we sampled 477 adult (females $n=168$ and males $n=309$ ) and 73 juvenile $B$. variegata. Sex was determined by the presence or absence of thumb pigmentation. Individuals without thumb pigmentation and an SUL $<35 \mathrm{~mm}$ were classified as juveniles. We also recorded the following pond variables: altitude (m), presence of aquatic invertebrate predators (Odonata and Coleoptera larvae), presence of pond vegetation, surrounding land cover (forest vs. pasture) and counted the number of $B$. variegata individuals at each pond. In general, surveyed ponds were small with simple vegetation structure, making it possible to count the number of individuals present at each pond at the time of sampling.

A residual body condition index (hereafter $\mathrm{BCI}$ ) was calculated following the methodology of Bancila et al. (2010), and the mean BCI value was computed for each pond (Fig. 2a). The relationship between body mass and SUL was curvilinear and both were $\log ^{10}$ transformed. We used an ANOVA to investigate whether females, males and juveniles differed in body condition. 

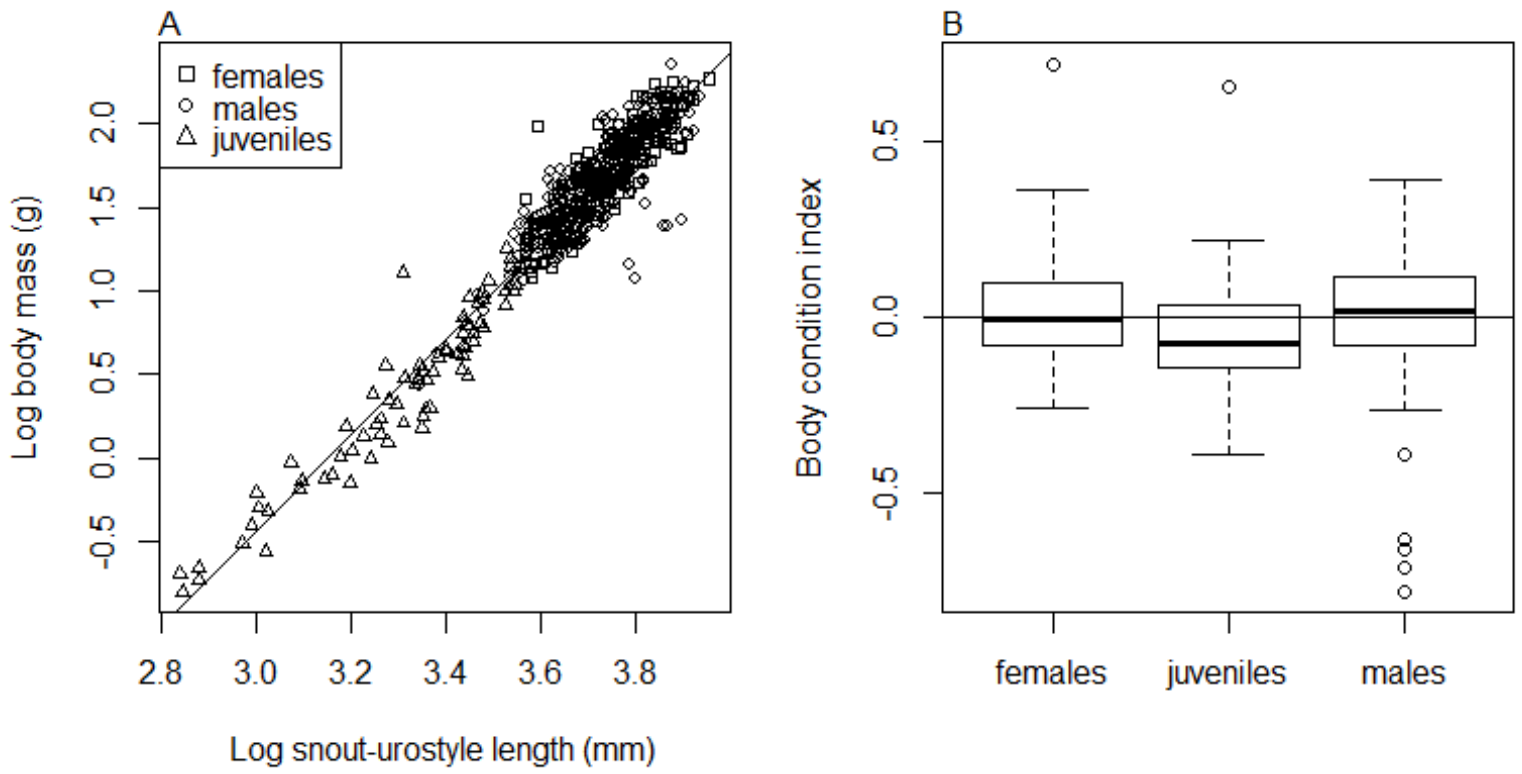

Fig. 2 (A) Relationship between body mass and snout-urostyle length in B. variegata. The points above the fitted line are toads with above average body condition and those below, have below average body condition. (B) Effects of sex and life stage on body condition

To investigate whether differences in pond averaged BCI could be explained by environmental variables we applied linear modelling using the log-scaled pond level BCI as the response variable and relevant pond attributes as explanatory variables. In the ANOVA outlined above, juveniles had lower body condition than adults and therefore we included the proportion of juveniles in each pond as an explanatory variable. Scatterplots were used prior to data analysis to assess potential collinearity between habitat variables. The model selection process involved non-automated backward selection which commenced with a full model (containing all explanatory variables) followed by the step-bystep deletion of non-significant variables $(\mathrm{P}>0.05)$ until only statistically significant variables remained. We used Pearson's correlation coefficient to investigate whether the relative abundance of individuals at a pond was associated with pond averaged body condition. All analyses were completed using R 2.10.0 (R Development Core Team 2009). 


\section{Results}

Females and males did not differ in body condition, but juveniles had significantly $(\mathrm{P}=0.00281)$ lower body condition (Fig. 2b). Land cover and the proportion of juveniles significantly predicted $\mathrm{BCI}$, with higher $\mathrm{BCI}$ in ponds located in forested landscapes and reduced $\mathrm{BCI}$ in ponds that had a high proportion of juveniles (Table 1, Fig. 3). There was no correlation between the relative abundance of individuals at a pond and pond averaged body condition (Pearson's correlation $\mathrm{r}=0.08$; not significant).

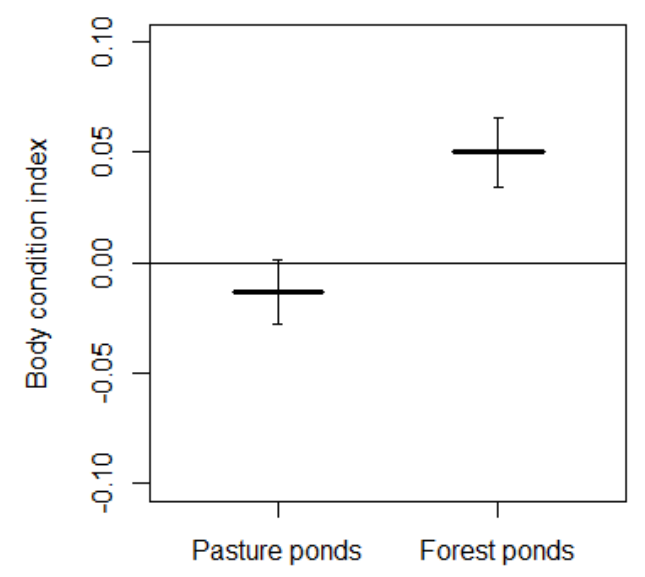

Fig. 3 Estimated body condition index means and standard errors for forest and pasture ponds

Table 1. Linear regression model for pond averaged body condition. The baseline of this model was "pasture landscape". The baseline of this model was "pasture landscape"

\begin{tabular}{lccc}
\hline Term & Estimate & Standard error & $p$-value \\
\hline Intercept & -0.01343 & 0.01343 & 0.35332 \\
Forested landscape & 0.06350 & 0.01894 & 0.00142 \\
Proportion juveniles & -0.11147 & 0.05390 & 0.04316 \\
\hline
\end{tabular}




\section{Discussion}

Landscape context was a significant predictor of body condition, with better body condition associated with toads from forested landscapes. This is in contrast to previous work from other regions that found B. variegata prefers open pasture ponds (e.g. Barandun and Reyer 1997), however, within the study region B. variegata appears to readily use both pasture and forest ponds (Hartel et al. $2007,2011)$. Ponds with a high proportion of juveniles were associated with lower pond averaged BCI. Juveniles may have reduced body condition because they have lower foraging efficiency and limited time to deposit energy reserves (Bancila et al. 2010).

Body condition can be influenced by short and long-term environmental stress (Janin et al. 2011). Better body condition in forest ponds may be related to higher resource availability, more humid micro-climatic conditions and greater water availability in forests than in pasture ponds. Despite the value of open pasture areas for the species (Barandun et al. 1997; Di Cerbo 2001; Hartel and von Wehrden 2013), it appears that ponds in forested landscapes provide particularly high quality habitat, at least in times of drought. Notably, body condition in amphibians during early spring is linked to resource intake during the previous autumn (Pope and Matthews 2002; Sztatecsny and Schabetsberger 2005). This suggests our results may not be strongly influenced by the dry conditions at the time of sampling, and may also apply to other years.

We found no correlation between pond averaged $\mathrm{BCI}$ and the relative abundance of $B$. variegata. This result may be explained by the propensity for toads to frequently move between ponds within the landscape separated by distances of up to $200 \mathrm{~m}$ (Hartel 2008). Therefore, the relative abundance of toads in a pond at one point in time is unlikely to be associated with body condition. Instead, high body condition might reflect the quality of the broader landscape that makes up an individual's home range, and resource intake during the preceding year (Sztatecsny and Schabetsberger 2005).

Internationally endangered species, such as B. variegata, are still common in traditional rural landscapes — but not all locations where the species is present provide equally valuable habitat. Based 
on our data, we suggest that body condition could be a useful proxy to investigate habitat quality. This is supported by Janin et al. (2011) who demonstrated that reduced body condition in common toad populations was associated with decreased habitat suitability resulting from fragmentation. Similarly, Sztatecsny and Schabetsberger (2005) found that body condition of the common toad was related to resource availability. One limitation of using a residual body condition index is that it is difficult to compare effect sizes between different studies—-something that is straightforward with absolute measures such as presence-absence data. We acknowledge that other variables (such as breeding success or lifetime reproductive output) could be even more useful than indices of body condition, but many demographic variables are logistically difficult to obtain. In combination with distribution information, measuring body condition therefore could be a useful tool to develop targeted conservation initiatives in regions where endangered species remain abundant. Acting to protect species before they are regionally endangered is most cost effective, and may provide the most realistic option to ensure the long-term persistence of biodiversity in traditional rural landscapes.

In conclusion, we note that the general approach used here could be applicable to other species that are still widespread in traditional landscapes, but have declined in already modernised, otherwise similar landscapes. That is, where presence and abundance data on their own are of limited value (because a given species is ubiquitous), such data can be complemented by other, more sophisticated measures, such as body condition or reproductive success. Obtaining such data—in addition to distribution data - therefore should be a high priority for species that are still common in traditional landscapes but have declined elsewhere.

\section{Acknowledgments}

The authors would like to thank two anonymous reviewers for helpful comments on an earlier version of this manuscript and $\mathrm{H}$. von Wehrden for insightful discussions. BS was supported by a Centre of Excellence for Environmental Decisions Early Career Researcher visiting fellowship. TH was supported by an Alexander von Humboldt postdoctoral fellowship. JF was supported by a Sofja Kovalevskaja Award by the Alexander von Humboldt Foundation. 


\section{References}

Bancila RI, Hartel T, Plaiasu R, Smets J, Cogalniceanu D (2010) Comparing three body condition indices in amphibians: a case study of yellow-bellied toad Bombina variegata. Amphibia-Reptilia $31: 558-562$

Barandun J, Reyer HU (1997) Reproductive ecology of Bombina variegata: characterisation of spawning ponds. Amphibia-Reptilia 18:143-154

Barandun J, Reyer HU, Anholt B (1997) Reproductive ecology of Bombina variegata: aspects of life history. Amphibia-Reptilia 18:347-355

Benton T, Hartel T, Settele J (2011) Warsaw Consensus Food security: a role for Europe. Nature 480:39-39

Canessa S, Oneto F, Ottonello D, Arillo A, Salvidio S (2013) Land abandonment may reduce disturbance and affect the breeding sites of an endangered amphibian in northern Italy. Oryx 47:280287

Di Cerbo A (2001) Ecological studies on Bombina v. variegata (Linnaeus, 1758) in Alpine habitats (Anura: Bombinatoridae). Biota 2:17-28

Dullinger S, Essl F, Rabitsch W, Erb KH, Gingrich S, Haberl H, Hulber K, Jarosık V, Krausmann F, Kuhn I (2013) Europe's other debt crisis caused by the long legacy of future extinctions. Proc Natl Acad Sci USA 110:7342-7347

Fischer J, Hartel T, Kuemmerle T (2012) Conservation policy in traditional farming landscapes. Conserv Lett 5:167-175

Hartel T (2008) Movement activity in a Bombina variegata population from a deciduous forested landscape. North-West J Zool 4:79-90

Hartel T, von Wehrden H (2013) Farmed areas predict the distribution of amphibian ponds in a traditional rural landscape. PLoS ONE 8:e63649-e63649. doi:10.1371/journal.pone.0063649 Hartel T, Nemes S, Mara G (2007) Breeding phenology and spatio-temporal dynamics of pond use by the yellow-bellied toad (Bombina variegata) population: the importance of pond availability and duration. Acta Zool Lit 17:56-63 
Hartel T, Bancila R, Cogalniceanu D (2011) Spatial and temporal variability of aquatic habitat use by amphibians in a hydrologically modified landscape. Freshw Biol 56:2288-2298

Hinam H, Clair C (2008) High levels of habitat loss and fragmentation limit reproductive success by reducing home range size and provisioning rates of Northern saw-whet owls. Biol Conserv 141:524535

Janin A, Lena JP, Joly P (2011) Beyond occurrence: body condition and stress hormone as integrative indicators of habitat availability and fragmentation in the common toad. Biol Conserv 144:1008-1016 Kuzmin S, Denoe"1 M, Anthony B, Andreone F, Schmidt B, Ogrodowczyk A, Ogielska M, Vogrin M, Cogalniceanu D, Kova'cs T, Kiss I, Puky M, Vo“ro“s J, Tarkhnishvili D, Ananjeva N (2009) Bombina variegata. IUCN 2013 red list of threatened species version 2013.1. www.iucnredlist.org. accessed 11 November 2013

Mikulcak F, Newig J, Milcu AI, Hartel T, Fischer J (2013) Integrating rural development and biodiversity conservation in Central Romania. Environ Conserv 40:129-137

Plieninger T, Bieling C (2012) Resilience and the cultural landscape: understanding and managing change in human-shaped environments. Cambridge University Press, Cambridge

Pope K, Matthews K (2002) Influence of anuran prey on the condition and distribution of Rana muscosa in the Sierra Nevada. Herpetologica 58:354-363

R Development Core Team (2009) R: a language and environment for statistical computing. R Foundation for Statistical Computing, Vienna Sztatecsny M, Schabetsberger R (2005) Into thin air: vertical migration, body condition, and quality of terrestrial habitats of alpine common toads, Bufo bufo. Can J Zool 83:788-796 